\title{
Toceranib phosphate-associated nephrotic syndrome in a dog: a case report
}

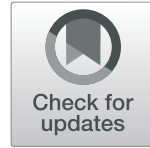

Shannon M. Remerowski ${ }^{1}$, Chamisa L. Herrera ${ }^{2}$ and Lindsay L. Donnelly ${ }^{1 *}$ (i)

\begin{abstract}
Background: Nephrotic syndrome (NS) is rare in dogs and is characterized by concurrent clinical findings of proteinuria, hyperlipidemia, hypoalbuminemia, and edema. NS has been reported in humans receiving tyrosine kinase inhibitors (TKI) and in dogs receiving masitinib. This is the first report of NS in a dog receiving toceranib phosphate.

Case presentation: An 8-year-old, female, spayed Labrador retriever was diagnosed with a $10 \mathrm{~cm}$ mast cell tumor on the left lateral abdomen. After completion of a 12-week vinblastine and prednisone protocol, she began treatment with toceranib phosphate $(2.6 \mathrm{mg} / \mathrm{kg}$ by mouth, every other day). Proteinuria was documented prior to starting toceranib. On day 426 after diagnosis (day 328 of toceranib phosphate treatment), the dog was evaluated for diarrhea, lethargy and anorexia. On physical examination, dependent edema was noted on the ventral chest and abdomen, and sterile neutrophilic inflammation was aspirated from a $2.3 \mathrm{~cm}$ splenic nodule. The following laboratory values were reported: albumin $<1.5 \mathrm{~g} / \mathrm{dL}$; cholesterol $378 \mathrm{mg} / \mathrm{dl}$ and urine protein to creatinine ratio of 3.79. The patient was diagnosed with NS, and treatment with toceranib phosphate was discontinued. Low-dose aspirin was started in addition to an increased dosage of enalapril $(0.47 \mathrm{mg} / \mathrm{kg}$ q12hr). No other therapy was instituted. The dog improved clinically, and laboratory values returned to near normal over the 8-week follow-up. She was euthanized 1399 days after discontinuing toceranib phosphate with progressive disease.

Conclusions: Nephrotic syndrome is a potential adverse event associated with the drug toceranib phosphate which may be reversible with discontinuation of treatment. Careful monitoring of urine protein, serum biochemistry, blood pressure and patient weight is advisable during treatment with toceranib phosphate.
\end{abstract}

Keywords: Toceranib phosphate, Dog, Nephrotic syndrome, Mast cell tumor, Proteinuria

\section{Background}

Nephrotic syndrome (NS) is the simultaneous development of hypoalbuminemia, hypercholesterolemia, proteinuria and edema or ascites and is a sequela of glomerular disease. NS has been described in human cancer patients receiving tyrosine kinase inhibitors (TKIs) [1-5]. Specifically, sunitinib is a molecule closely related to toceranib that has been associated with hypertension, minimal

\footnotetext{
* Correspondence: DonnellyL@missouri.edu

1 Department of Veterinary Medicine and Surgery, College of Veterinary Medicine, University of Missouri, 900 East Campus Drive, Columbia, MO 65211, USA

Full list of author information is available at the end of the article
}

change disease (MCD), collapsing Focal Segmental Glomerulosclerosis (cFSGS) and nephrotic syndrome [6-9]. Toceranib phosphate (Zoetis, Florham Park, New Jersey) is a veterinary TKI approved by the FDA for treatment of canine Patnaik grade II and III cutaneous or recurrent mast cell tumors and has reported activity against multiple malignancies. The primary mechanism of action is small molecule inhibition of vascular endothelial growth factor receptor 2 (VEGFR2), platelet-derived growth factor receptor- $\beta$ (PDGFR-ß), and Kit. Adverse renal effects of toceranib phosphate administration include azotemia, protein losing nephropathy (PLN) and hypertension [1012]. The development of NS in dogs receiving masitinib, a

C The Author(s). 2021 Open Access This article is licensed under a Creative Commons Attribution 4.0 International License, which permits use, sharing, adaptation, distribution and reproduction in any medium or format, as long as you give appropriate credit to the original author(s) and the source, provide a link to the Creative Commons licence, and indicate if changes were made. The images or other third party material in this article are included in the article's Creative Commons licence, unless indicated otherwise in a credit line to the material. If material is not included in the article's Creative Commons licence and your intended use is not permitted by statutory regulation or exceeds the permitted use, you will need to obtain permission directly from the copyright holder. To view a copy of this licence, visit http://creativecommons.org/licenses/by/4.0/ The Creative Commons Public Domain Dedication waiver (http://creativecommons.org/publicdomain/zero/1.0/) applies to the data made available in this article, unless otherwise stated in a credit line to the data. 
receptor tyrosine kinase inhibitor approved in Europe for use in dogs, has been described previously $[13,14]$. This is the first report of nephrotic syndrome developing in a dog receiving toceranib phosphate.

\section{Case report}

An 8-year-old, female, spayed Labrador retriever was presented to the University of Missouri Veterinary Health Center for treatment of a cytologically diagnosed mast cell tumor. On physical exam, a firm mass measuring $10 \mathrm{~cm}$ at longest diameter was present over the left lateral abdomen with concurrent ventral edema. The patient was lethargic with mild subjective hepatosplenomegaly. The remainder of the physical examination was unremarkable.

A complete blood count $(\mathrm{CBC})$ revealed a mature neutrophilia $\left(15.04 \times 10^{3 /} \mathrm{uL}\right.$ ref.: $\left.2.27-10.14\right)$, lymphopenia $\left(0.51 \times 10^{3} / \mathrm{uL}\right.$ ref.: $\left.0.76-4.23\right)$ and eosinopenia $(0.00 \times$ $10^{3} / \mathrm{uL}$ ref.: 0.08 to 1.1$)$. Abnormalities on a serum chemistry panel included: hypoalbuminemia $(2.6 \mathrm{~g} / \mathrm{dL}$ ref.: $2.9-4)$, hyperglobulinemia (4.2 g/dL ref.: $2.2-3.6)$, and hypocalcemia $(9.0 \mathrm{mg} / \mathrm{dL}$ ref.: 9.2-11.3). A urine sample was not obtained. Tumor grading and staging were recommended and declined.

Systemic treatment with vinblastine was started, and the dog received $2 \mathrm{mg} / \mathrm{m}^{2}$ intravenously on days 0,14 , $21,28,42,56,72$ and 84 for a total of 8 doses. A CBC was performed prior to each vinblastine administration. Except for a neutropenia on day 7 which delayed dose 2 until day 14, there were no significant complications. During this time, the following medications were administered: prednisone $(1.88 \mathrm{mg} / \mathrm{kg} \mathrm{PO}$ q24h from day 0 to $21 ; 1.5 \mathrm{mg} / \mathrm{kg}$ PO q24h from day 21 to $28 ; 1.0 \mathrm{mg} / \mathrm{kg}$ PO q24h from day 28 to day $98 ; 0.5 \mathrm{mg} / \mathrm{kg}$ PO q24h from day 98 to day 106), famotidine $(0.9 \mathrm{mg} / \mathrm{kg}$ PO q24h), diphenhydramine $(1.8 \mathrm{mg} / \mathrm{kg}$ PO q24h), tramadol $(1.8 \mathrm{mg} /$ $\mathrm{kg}$ PO q8-12h, as needed), and maropitant $(2.2 \mathrm{mg} / \mathrm{kg}$ PO q24h, as needed). By day 42 (vinblastine dose 5), the mass on her left lateral abdomen was $2 \mathrm{~cm}$ in diameter, an $80 \%$ reduction in longest length, and remained stable for the remainder of vinblastine treatment.

After completion of the 12-week vinblastine protocol (day 98), restaging was performed: $\mathrm{CBC}$, serum chemistry, urinalysis, urine protein-to-creatine ratio (UPC), abdominal ultrasound and cytology of the liver. The CBC was unremarkable, and the serum chemistry and urinalysis revealed the following abnormalities, in addition to those summarized in Table 1: hypochloremia $(107 \mathrm{mEq} /$ L ref.: 108-117), elevated anion gap ( $24 \mathrm{mEq} / \mathrm{L}$ ref.: $13-$ 22), elevated ALT (201 U/L ref.: 9-58), elevated alkaline phosphatase (ALP; 914 U/L ref.: 5-129), and elevated gamma glutamyl transferase (GGT; $33 \mathrm{U} / \mathrm{L}$ ref.: $0-5$ ). The USG was 1.010 with a UPC of 6.48 . The voided urine sediment was inactive. 4DX snap revealed all tests below detectable limits. An abdominal ultrasound was unremarkable except for mottled hepatic parenchyma. Cytologic evaluation of liver aspirates was consistent with steroid hepatopathy, and no evidence of mast cell infiltration was identified. Surgery, radiation, and/or medical management with toceranib phosphate were discussed. Treatment with toceranib phosphate was elected. Treatment was initiated at $65 \mathrm{mg}(2.6 \mathrm{mg} / \mathrm{kg}$ PO EOD) in addition to enalapril $(0.4 \mathrm{mg} / \mathrm{kg} \mathrm{PO}$ q24h) for management of the PLN. Recheck exam, CBC, serum chemistry, and urinalysis were recommended to occur at 4-6 week intervals either with the local veterinarian or the University of Missouri Veterinary Health Center. Visits to the University of Missouri were required to occur at least every 90 days. Available clinical assessments including albumin, cholesterol, UPC, BUN, and creatinine are summarized in Table 1 . At the day 120 recheck (day 22 of toceranib phosphate treatment), the mass measured $1.5 \mathrm{~cm}$ and remained stable for the duration of treatment with toceranib phosphate.

On day 399 (day 301 of toceranib phosphate treatment), the dog developed acute diarrhea, inappetence and lethargy. A toceranib phosphate drug holiday was recommended and metronidazole $(15 \mathrm{mg} / \mathrm{kg}$ PO q12h) was prescribed for seven days. One week later, stool

Table 1 Relevant laboratory values during treatment demonstrating criteria for NS developing 328 days after starting toceranib phosphate

\begin{tabular}{|c|c|c|c|c|c|c|c|c|c|}
\hline \multirow[b]{2}{*}{$\begin{array}{l}\text { Days post-presentation (Days post-toceranib phosphate } \\
\text { start) }\end{array}$} & \multicolumn{9}{|c|}{ Relevant laboratory values during treatment with toceranib phosphate } \\
\hline & $\begin{array}{l}98 \\
(0)\end{array}$ & $\begin{array}{l}120 \\
(22)\end{array}$ & $\begin{array}{l}182 \\
(84)\end{array}$ & $\begin{array}{l}262 \\
(164)\end{array}$ & $\begin{array}{l}331 \\
(233)\end{array}$ & $\begin{array}{l}426 \\
(328)\end{array}$ & $\begin{array}{l}434 \\
(336)\end{array}$ & $\begin{array}{l}449 \\
(351)\end{array}$ & $\begin{array}{l}477 \\
(379)\end{array}$ \\
\hline Albumin (g/dL) ref:: $2.9-4.0$ & 2.8 & 2.6 & 3.2 & 3.2 & 2.7 & $<1.5$ & 1.8 & 2.6 & 2.8 \\
\hline Cholesterol (mg/dL) ref:: 133-338 & 353 & 317 & 274 & 359 & 233 & 378 & $x$ & $x$ & $x$ \\
\hline UPC ref.: $<0.5$ & 6.48 & 2.03 & $x$ & $x$ & $x$ & 3.79 & 2.15 & 1.7 & 0.84 \\
\hline Edema & - & - & - & - & - & + & - & - & - \\
\hline BUN (mg/dL) ref:: 8-28 & 12 & $x$ & 16 & 11 & 14 & 21 & 20 & 18 & 17 \\
\hline Creatinine (mg/dL) ref:: 0.6-1.6 & 0.6 & $x$ & 0.9 & 1.0 & 1.1 & 1.1 & 0.9 & 0.9 & 0.9 \\
\hline
\end{tabular}

$\mathrm{x}$ indicates parameter not measured, - indicates parameter not present 
consistency had improved, but lethargy and inappetence persisted. On day 413 (day 315 of toceranib phosphate treatment), two weeks after stopping toceranib phosphate, the dog's appetite and demeanor was improved. Treatment resumed at the previous dose of $65 \mathrm{mg}$. Six days later, she, again, became inappetent and lethargic.

On day 426 (day 328 of toceranib phosphate treatment), the dog presented for evaluation. On physical examination, her left flank mast cell tumor measured $1.5 \mathrm{~cm}$. She had lost $3.5 \mathrm{~kg}$ from the last oncology recheck 90 days prior, resulting in an unintentionally increased toceranib phosphate dosage of $3.02 \mathrm{mg} / \mathrm{kg}$. At that time, a mass was palpated on the spleen, and dependent ventral edema was noted. The dog was normothermic. A CBC, serum chemistry, urinalysis, UPC, doppler blood pressure, abdominal ultrasound and cytology of the splenic mass were performed. A moderate, regenerative anemia was present (Hematocrit: 28\% ref.: 37-57\%). Significant abnormalities on serum chemistry and urinalysis included marked hypoalbuminemia, hypercholesterolemia and proteinuria (Table 1). The dog was hypertensive with a systolic blood pressure of 178 mmHg. Cytology of the $2.3 \mathrm{~cm}$ splenic mass revealed sterile, suppurative inflammation with some degenerate change. Surgical removal of the spleen was not recommended due to the patient's poor candidacy for anesthesia. Due to development of NS, toceranib phosphate was discontinued. Aspirin was prescribed (0.93 $\mathrm{mg} / \mathrm{kg}$ PO q24 hr), and the dosage of enalapril was increased $(0.47 \mathrm{mg} / \mathrm{kg}$ PO q12h). No other medications were prescribed.

The dog was seen for rechecks at 1 week, 3 weeks and 8 weeks post-diagnosis with NS. At each of these rechecks, a CBC, renal chemistry profile and UPC were conducted. The splenic mass was no longer palpable at the 1-week recheck; an ultrasound was not performed, and no further treatment of the splenic mass was pursued. Within 8 weeks of discontinuing toceranib phosphate, dependent edema resolved, UPC returned to near-normal and albumin levels significantly improved. (Table 1). Cholesterol was not rechecked. No further treatment was pursued for her mast cell tumor. She was euthanized 1825 days after diagnosis (1399 days after discontinuing toceranib phosphate) due to progressive disease of the original mast cell tumor in her left flank region.

\section{Discussion and conclusions}

Although less common than gastrointestinal adverse events, renal adverse events occur in a significant subset of dogs receiving TKIs. Proteinuria is a relatively common finding in dogs with cancer in general $[15,16]$. Data from a 2016 study on hypertension and proteinuria in toceranib phosphate-treated dogs found that dogs with cancer had an elevated UPC relative to dogs without cancer at baseline, but this difference was not significant [12]. PLN has been documented to occur in up to $24 \%$ of dogs receiving toceranib phosphate, and most cases are successfully managed with dose reductions, angiotensin converting enzyme (ACE) inhibitors, and drug holidays [11]. A study on the safety and efficacy of masitinib showed that dogs with pre-existing renal disease were more likely to develop severe renal adverse effects, including nephrotic syndrome, while taking the drug [13]. This has not been conclusively demonstrated with toceranib phosphate.

Most renal adverse events associated with administration of toceranib phosphate are mild. In this case, a PLN with a UPC of 6.48 was documented prior to starting toceranib phosphate, and risk of further renal injury was discussed. Ultimately, non-invasive treatment with toceranib phosphate was elected, and the tumor was wellcontrolled beyond the 328 days of toceranib administration. ACE inhibition was instituted, and subsequent UPC performed on day 22 of toceranib phosphate treatment was 2.03. Dipstick urine protein was measured on days 84,164 and 233 of toceranib phosphate treatment which were all negative or +1 , suggesting that the patient's proteinuria likely improved for the majority of toceranib phosphate treatment. However, given the lack of objective urine protein measurements, this cannot be confirmed.

In this case, it appears that NS was reversible with cessation of toceranib phosphate. Marked improvement in proteinuria and hypoalbuminemia with resolution of edema after cessation of toceranib phosphate treatment supports that NS was likely an adverse event related to TKI therapy. Other than discontinuing toceranib phosphate, the only treatment this patient received was increasing enalapril dosing from SID to BID. By the 8week recheck, the patient's UPC was 0.84 , and her hypoalbuminemia had improved markedly. This is consistent with the reported response of the dog that developed NS while being treated with masitinib [14]. In humans, most cases of NS resolved with discontinuation of TKI therapy or change to an earlier generation TKI that did not target VEGF [2, 5, 17]. However, renal dysfunction was irreversible in some cases [4, 7]. In those cases, length of TKI therapy with concomitant persistent proteinuria and cumulative glomerular damage was hypothesized to play a role. In the case reported here, NS developed after nearly a year of treatment with toceranib phosphate, and she had proteinuria prior to starting the drug. Preexisting PLN likely increases the risk of NS secondary to TKIs.

Rechecks at the referral institution and dosage adjustments were performed every 3 months. Between referral visits, recheck exams and laboratory assessments were 
performed with the local veterinarian. Ideally, rechecks and dosage adjustments for dogs receiving tyrosine kinase inhibitors are performed every $4-6$ weeks. The dog lost $3.4 \mathrm{~kg}$ in the 3 months prior to NS diagnosis. Perhaps gastrointestinal signs caused the weight loss, or gastrointestinal signs and NS may have been a result of the relative dose increase of toceranib phosphate. The dosage of toceranib phosphate at the time of NS development was $3.02 \mathrm{mg} / \mathrm{kg}$ which was an increase of $16 \%$. The labeled dosage of toceranib phosphate is $3.25 \mathrm{mg} /$ $\mathrm{kg}$, but a dosage range of $2.4 \mathrm{mg} / \mathrm{kg}$ to $2.9 \mathrm{mg} / \mathrm{kg}$ EOD was found to minimize adverse effects while still reaching a plasma concentration in excess of the minimum concentration required for target inhibition [18].

Interestingly, the dog was diagnosed with a $2.3 \mathrm{~cm}$ splenic mass during the same visit that confirmed NS. Cytologic evaluation revealed sterile suppurative inflammation. No organisms were identified on cytology, but degenerate neutrophils were observed suggesting infection may have been present. No antimicrobial therapy was instituted, and this mass never caused clinical signs. The potential impact of splenic inflammation on the clinical picture was considered, but given the lack of fever, inflammatory leukogram, abdominal fluid or decline in patient status without treatment, the contribution is presumed to be minimal. In humans, secondary bacterial infections are a common complication of NS, particularly in children [19-21]. In one study, $40 \%$ of children hospitalized with NS had at least 1 infection [20]. Although infection has been reported in adults with NS, less data is available on incidence and treatment [22]. In the veterinary literature, there are no reports of secondary bacterial infection in patients with NS [23, 24]. Based on human studies, it is possible that splenic inflammation or infection was a complication of NS in this patient.

The mechanism for PLN development in patients being treated with TKIs is not well understood but is hypothesized to involve podocyte damage. Renal biopsies from humans who developed glomerular disease during TKI therapy showed evidence of podocytopathies, including focal segmental glomerulosclerosis (FSGS) and minimal change disease (MCD). MCD is a leading cause of NS development in children [6, 25]. Inhibition of tyrosine phosphorylation of nephrin, a podocyte protein present in the slit diaphragm, may be implicated in the observed podocyte injury [6].

There are limited medical treatments available for management of biologically aggressive mast cell tumors, and toceranib phosphate is an easily-administered, noninvasive choice with an objective response rate of $43 \%$ [10]. Patients should be routinely screened for proteinuria, hypertension and renal insufficiency prior to beginning treatment with toceranib phosphate. Careful monitoring of blood pressure, UPC and serum chemistry is indicated throughout treatment. Furthermore, frequent monitoring of patient weight with dose adjustments, as necessary, to remain in the range of $2.4 \mathrm{mg} / \mathrm{kg}$ to $2.9 \mathrm{mg} / \mathrm{kg}$ EOD is advisable.

\section{Abbreviations \\ NS: Nephrotic syndrome; TKI: Tyrosine kinase inhibitor; PLN: Protein losing nephropathy; PO: Per os; EOD: Every other day; FDA: Food and Drug Administration; CBC: Complete blood count; FSGS: Focal segmental glomerulosclerosis; MCD: Minimal change disease; UPC: Urine protein-to- creatinine ratio; ACE: Angiotensin converting enzyme; ALT: Alanine transaminase; ALP: Alkaline phosphatase; GGT: Gamma-glutamyl transferase; BUN: blood urea nitrogen}

\section{Acknowledgements}

Not applicable.

\section{Authors' contributions}

SR was a major contributor in writing the manuscript. LD was a major contributor in writing and editing the manuscript. CH was a major

contributor in data acquisition and manuscript revision. All authors read and approved the final manuscript.

\section{Funding}

Not applicable.

\section{Availability of data and materials}

All relevant data are within this paper. The data generated during the current case study are available from the corresponding author on reasonable request.

\section{Declarations}

Ethics approval and consent to participate Not applicable.

\section{Consent for publication}

Written informed consent for publication of the clinical details was obtained from the dog's owner.

\section{Competing interests}

The authors declare that they have no competing interests.

\section{Author details}

'Department of Veterinary Medicine and Surgery, College of Veterinary Medicine, University of Missouri, 900 East Campus Drive, Columbia, MO 65211, USA. ²Boundary Bay Veterinary Specialty Hospital, 4176 Meridian Street, Bellingham, WA 98226, USA.

Received: 15 February 2021 Accepted: 24 March 2021

Published online: 07 April 2021

\section{References}

1. Ruebner RL, Copelovitch L, Evageliou NF, Denburg MR, Belasco JB, Kaplan BS. Nephrotic syndrome associated with tyrosine kinase inhibitors for pediatric malignancy: case series and review of the literature. Pediatr Nephrol. 2014;29(5):863-9. https://doi.org/10.1007/s00467-013-2696-0.

2. Ochiai S, Sato Y, Minakawa A, Fukuda A, Fujimoto S. Dasatinib-induced nephrotic syndrome in a patient with chronic myelogenous leukemia: a case report. BMC Nephrol. 2019;20(1):87. https://doi.org/10.1186/s12882-01 9-1273-6.

3. Mandac Rogulj I, Matišić V, Arsov B, Boban L, Juginović A, Molnar V, et al. Dasatinib-induced nephrotic syndrome: a case of phenoconversion. Croat Med J. 2019;60(3):250-4. https://doi.org/10.3325/cmj.2019.60.250.

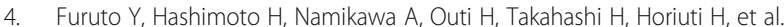
Focal segmental glomerulosclerosis lesion associated with inhibition of tyrosine kinases by lenvatinib: a case report. BMC Nephrol. 2018;19(1):273. https://doi.org/10.1186/s12882-018-1074-3. 
5. Maruyama K, Chinda J, Kuroshima T, Kabara M, Nakagawa N, Fujino T, et al. Minimal change nephrotic syndrome associated with gefitinib and a successful switch to erlotinib. Intern Med. 2015;54(7):823-6. https://doi.org/1 0.2169/internalmedicine.54.3661.

6. Estrada CC, Maldonado A, Mallipattu SK. Therapeutic inhibition of VEGF signaling and associated Nephrotoxicities. J Am Soc Nephrol. 2019;30(2): 187-200. https://doi.org/10.1681/ASN.2018080853.

7. Takahashi D, Nagahama K, Tsuura Y, Tanaka H, Tamura T. Sunitinib-induced nephrotic syndrome and irreversible renal dysfunction. Clin Exp Nephrol. 2012;16(2):310-5. https://doi.org/10.1007/s10157-011-0543-9.

8. Jha PK, Vankalakunti M, Siddini V, Bonu R, Prakash GK, Babu K, et al. Sunitinib induced nephrotic syndrome and thrombotic microangiopathy. Indian J Nephrol. 2013;23(1):67-70.

9. Quintyne Kl, Neenan T, Casserly L, Gupta R. Uncommon side effect with a commonly used targeted agent: sunitinib-induced nephrotic syndrome in a patient with metastatic renal cell carcinoma. BMJ Case Rep. 2014;2014: bcr2013201183.

10. London CA, Malpas PB, Wood-Follis SL, Boucher JF, Rusk AW, Rosenberg MP, et al. Multi-center, placebo-controlled, double-blind, randomized study of oral toceranib phosphate (SU11654), a receptor tyrosine kinase inhibitor, for the treatment of dogs with recurrent (either local or distant) mast cell tumor following surgical excision. Clin Cancer Res. 2009;15(11):3856-65. https://doi.org/10.1158/1078-0432.CCR-08-1860.

11. Piscoya SL, Hume KR, Balkman CE. A retrospective study of proteinuria in dogs receiving toceranib phosphate. Can Vet J. 2018;59(6):611-6.

12. Tjostheim SS, Stepien RL, Markovic LE, Stein TJ. Effects of toceranib phosphate on systolic blood pressure and proteinuria in dogs. J Vet Intern Med. 2016;30(4):951-7. https://doi.org/10.1111/jvim.13951.

13. Hahn KA, Ogilvie G, Rusk T, Devauchelle P, Leblanc A, Legendre A, et al. Masitinib is safe and effective for the treatment of canine mast cell tumors. J Vet Intern Med. 2008;22(6):1301-9. https://doi.org/10.1111/j.1939-1676.2008.0190.x.

14. Devine L, Polzin DJ. Presumed masitinib-induced nephrotic syndrome and azotemia in a dog. Can Vet J. 2016;57(7):752-6

15. Crivellenti LZ, Silva GE, Borin-Crivellenti $S$, Cianciolo R, Adin CA, Dantas M, et al. Prevalence of glomerulopathies in canine mammary carcinoma. PLoS One. 2016;1 1(10):e0164479. https://doi.org/10.1371/journal.pone.0164479.

16. Di Bella A, Maurella C, Cauvin A, Schmidt JM, Tapia BB, North SM. Proteinuria in canine patients with lymphoma. J Small Anim Pract. 2013;54(1):28-32.

17. Izzedine H, Escudier B, Lhomme C, Pautier P, Rouvier P, Gueutin V, et al. Kidney diseases associated with anti-vascular endothelial growth factor (VEGF): an 8year observational study at a single center. Medicine (Baltimore). 2014;93(24): 333-9. https://doi.org/10.1097/MD.0000000000000207.

18. Bernabe LF, Portela R, Nguyen S, Kisseberth WC, Pennell M, Yancey MF, et al. Evaluation of the adverse event profile and pharmacodynamics of toceranib phosphate administered to dogs with solid tumors at doses below the maximum tolerated dose. BMC Vet Res. 2013;9(1):190. https://doi. org/10.1186/1746-6148-9-190

19. Wu HM, Tang JL, Cao L, Sha ZH, Li Y. Interventions for preventing infection in nephrotic syndrome. Cochrane Database Syst Rev. 2012;2012(4):Cd003964.

20. Wei CC, Yu IW, Lin HW, Tsai AC. Occurrence of infection among children with nephrotic syndrome during hospitalizations. Nephrology (Carlton). 2012;17(8):681-8. https://doi.org/10.1111/j.1440-1797.2012.01650.x.

21. Carpenter SL, Goldman J, Sherman AK, Selewski DT, Kallash M, Tran CL, et al. Association of infections and venous thromboembolism in hospitalized children with nephrotic syndrome. Pediatr Nephrol. 2019:34(2):261-7.

22. Kodner C. Diagnosis and management of nephrotic syndrome in adults. Am Fam Physician. 2016;93(6):479-85.

23. Klosterman ES, Moore GE, de Brito Galvao JF, DiBartola SP, Groman RP, Whittemore JC, et al. Comparison of Signalment, Clinicopathologic findings, histologic diagnosis, and prognosis in dogs with glomerular disease with or without Nephrotic syndrome. J Vet Intern Med. 2011;25(2):206-14. https:// doi.org/10.1111/j.1939-1676.2010.0669.x

24. Klosterman ES, Pressler BM. Nephrotic syndrome in dogs: clinical features and evidence-based treatment considerations. Top Companion Anim Med. 2011;26(3):135-42. https://doi.org/10.1053/j.tcam.2011.04.004.

25. Vivarelli M, Massella L, Ruggiero B, Emma F. Minimal change disease. Clin J Am Soc Nephrol. 2017;12(2):332-45. https://doi.org/10.2215/CJN.05000516.

\section{Publisher's Note}

Springer Nature remains neutral with regard to jurisdictional claims in published maps and institutional affiliations.

\section{Ready to submit your research? Choose BMC and benefit from:}

- fast, convenient online submission

- thorough peer review by experienced researchers in your field

- rapid publication on acceptance

- support for research data, including large and complex data types

- gold Open Access which fosters wider collaboration and increased citations

- maximum visibility for your research: over $100 \mathrm{M}$ website views per year

At BMC, research is always in progress.

Learn more biomedcentral.com/submissions 